\title{
Editorial Spinal Paralysis Services
}

As the Council of the International Medical Society knows, and the Members of the Society know, it has been my intention to encourage contributions from Members of the Society and indeed also I would say now, from other doctors not necessarily Members of the Society, to submit profiles of 'Spinal Paralysis Services', for publication in Paraplegia; the idea being that such information could be of great value to all doctors and other medical and paramedical personnel involved with the care of those with serious spinal injury or disease. I have had 'firm offers' of such profiles from several Members of the Society, and am eagerly awaiting these. I am delighted to have received the profile from $\mathrm{Dr}$ W. E. Davies, Director of the new Spinal Injuries Unit in Brisbane, Queensland, Australia, and have pleasure in accepting this publication for this issue of Paraplegia. I know that it will prove valuable to many workers in the field of spinal injury and disease, and again would strongly encourage others to submit to me profiles of their spinal paralysis service unit or department giving an outline of the location, functions, physical facilities, philosophy, staffing, basic and clinical research activities, educational aspects, relationships to other departments and specialties in hospitals, and the type of population served and the area of country and nature of the country where the unit is established. Also, if at all possible, some brief history of the development of the spinal service or unit or department, and in addition, some aspects concerning the future plans for the further activities and development of that particular spinal injury service. I strongly feel that such a series of articles would be most important for all of us involved in the very wide and important field of Paraplegia. We have a great deal to learn from each other. Thus I and my Editorial Board await further submissions from Directors or Heads or senior doctors of such Services, and would like to publish these and of course, if at all possible, wish to have a general outline of the actual plans of such units, and some photographs of the buildings, possibly including one or two photographs of particular aspects of the 'inside' of the units, for example the hydrotherapy and physiotherapy department, laboratories and research areas, urodynamic facilities, etc. Again I am most grateful to Dr Davies for initiating this series.

Phillip Harris Editor 